\title{
A profile of birth defects in a tertiary care center and focus on preventable causes: a cross sectional observational study
}

\author{
Chekkali C.M. ${ }^{1}$, Kankanala G.R. ${ }^{2}$, Rakesh K ${ }^{3}$, Singh H. ${ }^{4}$ \\ ${ }^{1}$ Dr. Chandra Mohan Chekkali, Associate Professor of Pediatrics, ${ }^{2}$ Dr. Greeshma Reddy Kankanala, Senoir Resident in \\ Pediatrics, ${ }^{3}$ Dr. Rakesh Kotha, Assistant Professor of Neonatology, ${ }^{4}$ Dr. Himabindu Singh, Professor of Neonatology, all \\ authors are affiliated with Niloufer Hospital, Hyderabad, Telangana, India.
}

Corresponding Author: Dr. Rakesh Kotha, Assistant Professor, Department of Neonatology, Niloufer Hospital, Hyderabad Telangana, India. E-mail: dr.rakeshkotha@gmail.com

\begin{abstract}
Introduction: Birth defects may be defined as "all structural, biochemical and functional disorder present at birth". The worldwide incidence of congenital malformations is estimated at $15-30$ per 1000 births. Congenital malformation is already the leading cause of infant mortality in United States. In India prevalence is about 60 to 70 per 1000 live births. Epidemiological studies of specific congenital malformations will provide information for the planning, provision and evaluation of health services. That's why in this study we want to evaluate clinical profile of birth defects. We also focused on preventable causes of congenital anomalies Aim: To know the profile of birth defects among the newborns born in a tertiary care center and look for the preventable causes associated with birth defects. Methodology: crosssectional prospective observational study done during 2018 September to 2019 September done at Niloufer hospital Hyderabad. In the present study only intramural babies were included, both live and still born babies were included. Statistical analysis done by SPSS version 20. Results: Incidence of congenital anomalies in the present study is 22.43 per 1000 births. Central nervous system malformation is found to be the commonest malformation (24.63\%). Followed by cardiovascular malformations (20.15\%), Gastrointestinal system (17.91\%) and musculoskeletal system (17.91\%). Among the central nervous system malformations spina bifida (44.48\%) was found to be the commonest malformation. The incidence of CNS malformation was 6.16 per 1000 births. In cardiovascular system ventricular septal defects, in gastrointestinal system cleft lip and palate and in musculoskeletal system congenital talipes equino varus were the most common birth defects. Conclusion: Most common congenital anomaly in our hospital was central nervous system malformations followed by cardiovascular system. One of the major portions of birth defects were caused by preventable casues.
\end{abstract}

Keywords: Birth defects, Neonate, Congenital anomalies, Malformations, Epigenitics

\section{Introduction}

The word "congenital" comes from Greek word congenitus, i.e. born with malformation - any structure that is abnormal in form. "Anomaly" from word Anomelia, i.e. irregularity or deviation from normal. Congenital malformations may be defined as "abnormalities of structures present at birth and attributable to faulty development". Congenital anomaly may be defined as "all structural, biochemical and functional disorder present at birth". Thus, the term "malformation" must be limited to the disturbance of structures recognizable with the naked eye. Birth

Manuscript received: $4^{\text {th }}$ September 2019

Reviewed: $14^{\text {th }}$ September 2019

Author Corrected: $20^{\text {th }}$ September 2019

Accepted for Publication: $25^{\text {th }}$ September 2019 defects are different types like Malformations, Disruptions, Deformations, Dysplasia, Malformation Syndrome, Malformation, Sequence and Association. It is estimated that each year, more than 4 million children are born with serious birth defects that cause death or lifelong disability for the patient and hardship for entire families [1,2]. Birth defects have a great impact in middle- and low-income countries like India. Birth defects have a great impact in middle- and low-income countries.

Ninety four percent of birth defects in newborns worldwide and 95 percent of deaths due to birth defects worldwide occur in these countries. In India, it is

Pediatric Review: International Journal of Pediatric Research Available online at: www.medresearch.in 474|P a g e 


\section{Original Research Article}

estimated that the prevalence of birth defects is 61 to 69.9 per 1000 live births [3]. About one in every 33 babies is born with a birth defect. Birth defects are a leading cause of infant death accounting for more than 1 of every 5 infant deaths in world. The loss of pregnancy or birth of a malformed baby is an emotional and traumatic experience which can lead to psychological problems and mothering difficulties.

In addition, babies born with birth defects have a greater chance of illness and long-term disability than babies without birth defects Factors affecting birth defects can be genetic and non-genetic. There are well established preventive programs which are addressing non genetic factors influencing birth defects in developed countries however in India limited preventive strategies of birth defects are in place due to limited information on factors determining the occurrence of birth defects. This study intends to come out with additional findings as regard to factors associated with birth defects and hence supplement to the already ongoing strategies. The results of the study will add to the knowledge available for the development of a comprehensive intervention package for birth defects.

\section{Aims and Objectives}

To know the profile of birth defects among the newborns born in a tertiary care center and look for the preventable causes associated with birth defects

\section{Materials and Methods}

Type and period of study: The present study was cross sectional observational study carried out for a period of 12 months from September 2018 to September 2019 at Department of Neonatology, Niloufer hospital, Hyderabad for evidence of clinically detectable congenital malformations which includes both live and still born infants

\section{Inclusion criteria}

All newborns born in Niloufer hospital were included

\section{Exclusion criteria}

Newborns born outside Niloufer hospital were excluded

Study design: A discrete clinical screening of all newborn was done within 24 hours of birth and a further examination were done within 24 hours before discharging the live born babies from the hospital for evidence of any congenital malformations and were duly recorded. In those infants with malformations a detailed history as per proforma was performed

Sample size: Sample size justified as 120 by calculated at alpha error 0.05 and power 80 by open eps info $[4,5]$

\section{Statistical analysis:}

All statistical analysis was carried out at $5 \%$ level of significance and $\mathrm{p}$ value $<0.05$ by SPSS version 20

\section{Results}

The total numbers of births studied were 5572. The number of malformations were noted separately among live births and stillborn. Among the 5572 consecutive births (both liveborn and stillborn), 2860 were male babies and 2707 were female babies, five were ambiguous. Out of which 120 infants had congenital malformations corresponding to $2.15 \%$ with incidence of 22.43 per 1000 live births. In 120 malformed babies, 56 were male babies and 59 were female babies, in 5 babies' sex of the baby was not made out because of ambiguous genitalia. Out of these 120 babies, 134 malformations were seen (25 per 1000 live births). The total numbers of liveborn were 5349 out of which 106 infants had 111 malformations. The total numbers of stillborn were 223 out of which 14 infants had 23 malformations

There were 58 twin births among 5572 births. Malformations were seen in 1 twin birth. A total of 134 malformations were noted in 120 malformed babies. Many babies had more than one malformation of different systems placed under separate groups making the total number of congenital malformations to 134. It is observed that the more number of malformations observed in female babies compared to male babies in the present study but it was not statistically significant $(\mathrm{P}>0.05)$

It is observed that the greater number of malformations observed in the mothers in the age group of 26-30 years followed by 21-25 years and it is statistically Significant $(\mathrm{P}<0.05)$.

It is observed that the more number of malformations observed in babies born out of non-consanguineous marriage compared to babies born out of consanguineous marriage in the present study, it is statistically significant $(\mathrm{P}<0.05)$. There were a greater number of malformations observed in first gravida and it is statistically significant $(\mathrm{P}<0.05)$ 
Table 1: Maternal illness and congenital malformations.

\begin{tabular}{|l|c|c|}
\hline Maternal Illness & Number & Percentage \\
\hline Epilepsy & 05 & 4.17 \\
\hline Diabetes & 03 & 2.5 \\
\hline Heart disease & 02 & 1.67 \\
\hline Hypertension & 06 & 5 \\
\hline Stroke & 02 & 1.67 \\
\hline Polyhydramnios & 07 & 5.83 \\
\hline Oligohydramnios & 09 & 7.5 \\
\hline Thyroid disorder & 12 & 10 \\
\hline
\end{tabular}

Maternal illness were present in $41(34.16 \%)$ of mothers and 5 mothers had more than one maternal illness. Most common antenatal factor were thyroid disorder (10\%) followed by oligohydramnios $(7.5 \%)$ followed by polyhydramnios $(5.83 \%)$ followed by gestational hypertension $(5 \%)$.

Thirty three percentage (100 out of 120) of the mothers were on regular ANC follow up (booked cases) with minimum 3 antenatal visits and 94\% (113 out of 120) of the mothers underwent antenatal ultrasonography.

Fifty-seven percentage ( 69 out of 120) of the mothers had minimum of 2 antenatal ultrasound scans and $89.17 \%$ (107 out of 120) of the mothers had folic acid intake

Table 2: Antenatal factors and congenital malformations.

\begin{tabular}{|l|c|c|}
\hline Antenatal factors & Number & Percentage \\
\hline Alcohol consumption & 05 & 4.17 \\
\hline Smoking & 01 & 0.83 \\
\hline Exposure to radiation & 02 & 7.67 \\
\hline Fever with rash in 6 months prior to conception & 09 & 7.5 \\
\hline Usage of teratogenic drugs & 09 & 7.5 \\
\hline
\end{tabular}

Usage of teratogenic drugs $(7.5 \%)$ and fever with rash $(7.5 \%)$ in six months prior to conception found to be most common antenatal factor in present study followed by alcohol consumption $(4.17 \%)$

In present study a greater number of malformations are seen in mothers who were vaccinated. Bad obstetric history was seen in 42 cases (35\%) among them $66.67 \%$ had previous abortions and $33.33 \%$ had previous birth defects. More number of malformations were seen in preterm babies (70) (58.33\%) than the term babies (50) (41.66\%).

Thus, it is observed that central nervous system malformations were the leading manifestation of congenital malformations followed by the cardiovascular system, musculoskeletal system, gastrointestinal system, genitourinary system, eye, ear and face malformations and respiratory system

Among the central nervous system malformations, spina bifida (44.48\%) was found to be the commonest malformation. Among the respiratory system congenital emphysema (33.3\%), congenital cystic adenomatoid malformations (33.3\%) were common

Pediatric Review: International Journal of Pediatric Research Available online at: www.medresearch.in 476|P a g e 
Table-3: System wise distribution of congenital anomalies $(n=134)$.

\begin{tabular}{|c|c|c|c|c|c|c|c|c|}
\hline \multirow[t]{2}{*}{ Type of Malformation } & \multirow{2}{*}{$\begin{array}{c}\text { No. } \\
\text { of } \\
\text { cases }\end{array}$} & \multicolumn{3}{|c|}{ Live born } & \multicolumn{3}{|c|}{ Stillborn } & \multirow[t]{2}{*}{ Percentage } \\
\hline & & Male & Female & Ambiguous & Male & Female & Ambiguous & \\
\hline CNS & 33 & 07 & 17 & 00 & 04 & 03 & 02 & 24.63 \\
\hline Cardiovascular system & 27 & 12 & 13 & 00 & 02 & 00 & 00 & 20.15 \\
\hline Gastrointestinal system & 24 & 08 & 12 & 02 & 00 & 02 & 00 & 17.91 \\
\hline Musculoskeletal system & 24 & 10 & 08 & 00 & 06 & 00 & 00 & 17.91 \\
\hline Respiratory system & 03 & 00 & 03 & 00 & 00 & 00 & 00 & 2.24 \\
\hline Genitourinary system & 08 & 03 & 00 & 03 & 00 & 00 & 02 & 5.97 \\
\hline $\begin{array}{l}\text { Eye, ear \& face } \\
\text { malformations }\end{array}$ & 05 & 02 & 03 & 00 & 00 & 00 & 00 & 3.73 \\
\hline Miscellaneous & 10 & 03 & 05 & 00 & 00 & 01 & 01 & 7.46 \\
\hline Total & 134 & 45 & 61 & 05 & 12 & 06 & 05 & 100 \\
\hline
\end{tabular}

Among the cardiovascular malformation's ventricular septal defects (11.12\%), atrial septal defects (11.12\%), dextrocardia (11.12\%), tetrology of fallot (11.12\%), transposition of great arteries $(11.12 \%)$ had equal incidence. Among the syndrome's downs syndrome and Pierre Robbin syndrome were more common (22\% each). Among the gastrointestinal malformations cleft lip and palate $(58.32 \%)$ was found to be the commonest malformation. Among the musculoskeletal malformations CTEV (33.33\%) was found to be commonest. Among the genitourinary malformations ambiguous genitilia $(62.5 \%)$ was found to be commonest

\section{Discussion}

Incidence of congenital anomalies in the present study is 22.43 per 1000 birth compared to Patel $\mathrm{ZM}$ et al 16 [4], Bhat BV et al 37 [5] Neelambari YC et al 12 [6] and Verma et al 36 [7]. The wide variation in the incidence of malformations between different studies is due to various factors such as population sampled, geographical and racial differences selection of casesliveborn, stillborn or both and age of the baby when diagnosis is made.

The variation in incidence is because of poor nutritional status, poor antenatal care, early marriage, consanguinity educational status of the parents etc. Incidence of congenital malformations in liveborn in present study was 1.98 similar to incidence seen in Patel ZM et al 1.6 [4] and Agarwal SS et al 1.6 [8] and relatively more than other studies. Incidence of congenital malformation was lesser in stillborn in present study 10.3 in contrast to other studies by Patel ZM et al 15.8 [4], Bhat B V et al 15.7 [5], Grover N et al 15.1 [9] and Agarwal et al 16.4 [8]

Central nervous system malformation is found to be the commonest malformation in the present study due to more incidence of spina bifida, anencephaly and encephalocele. This is similar to the studies conducted by Grover $\mathrm{N}$ et al [9], Tapan Pattanaik et al [10]. The incidence of CNS malformation was found to be higher in the present study 6.16 per 1000 births than other studies due to higher incidence of anencephaly and neural tube defects. This may be both due to environmental factors, consanguinity, unsupervised drug intake etc.

Among the central nervous system malformations present study shows higher incidence of spina bifida whereas studies by Tapan Pattanaik et al [10] showed higher incidence of hydrocephalus and anencephaly. According to the study conducted by Neelambari YC et al [6] anencephaly followed by myelomeningocele showed higher incidence

Cardiovascular system malformations were found to be second most common malformation in present study 5.04 per 1000 births. Incidence in present study is similar to studies by Chaturvedi $\mathrm{P}$ et al 6.45 per 1000 births 9 [11]. Among the cardiovascular malformations present study shows equally higher incidence of ventricular septal defect, atrial septal defect, transposition of great arteries, dextrocardia, tetralogy of 


\section{Original Research Article}

Fallot. In the studies conducted by Neelambari YC et al [6] ventricular septal defect, patent ductus arteriosus showed higher incidence. According to the study conducted by Taksande et al [12] acyanotic heart disease showed higher incidence. The incidence of musculoskeletal malformations was found to be 4.48 per 1000 live births. The incidence in the present study was comparable to the incidence noted in study conducted by Taksande et al [12].

Among the musculoskeletal malformations in the present study congenital talipes equino varus was found to be commonest. According to the study by Tapan Pattanaik et al [10] congenital talipes equino varus followed by syndactyly was found to be commonest. According to Taksande et al [12] Polydactyly/ syndactyly followed by CTEV showed higher incidence

Incidence of gastrointestinal malformation was found to be 4.48 per 1000 births which is similar to studies done by Neelambari YC et al 4.95 per 1000 live births [6], Bhat B V et al 5.47 per 1000 live births [5]. The incidence is low compared to other studies due to lack of autopsy facilities. In the present study cleft lip and cleft palate was found to show higher Incidence.

According to the studies conducted by Taksande et al. Neelambari YC et al, Tapan Pattanaik et al the commonest gastrointestinal malformation was found to be cleft lip and cleft palate which is similar to the present study $[6,10,12]$. This can be due to easy identification of cleft lip and palate in contrast to other gastrointestinal malformations which require autopsy or radiological diagnosis

Incidence of Genitourinary malformation was found to be 1.49 per 1000 births. Study done by Tapan pattnaik et al showed similar incidence 1.12 per 1000 births [10] The low incidence is due to lack of autopsy facilities which could have detected more internal malformations of the genitourinary tract. According to the study conducted by Tapan Pattanaik et al hydronephrosis was the commonest among genitourinary malformations [10].

According to studies by Neelambari YC et al and Taksande et al hypospadiasis showed highest incidence $[6,12]$. In present study ambiguous genitilia showed highest incidence among the genitourinary system malformations. This can be due to easy detectability of malformation of the external genitilia in contrast to other genitourinary malformations which require autopsy or radiological diagnosis. Incidence of eye ear and face malformations was found to be 0.93 per 1000 births. Incidence in present study is comparable to the studies done by Tapan Pattanaik et al. Present study and studies by Taksande et al showed microphthalmos to be the commonest $[10,12]$. Incidence of respiratory system malformations was found to be 0.5 per 1000 births. Incidence in present study is comparable to studies done by Taksande et al [12].

Thus, incidence of congenital malformations were maximum in primigravida as noted by $\mathrm{Bhat} \mathrm{B} \mathrm{V}$ et al and Grover $\mathrm{N}$ et al and also in the present study malformations were more in primigravida followed by second gravida. Tapan Pattanaik et al and Chaturvedi et al noticed more common in gravida 4 and above mothers $[5,9,10]$.

This may be because of previous bad obstetrics history (42 cases), poor antenatal care, and unpreparedness of the mother for pregnancy, unplanned pregnancy, and poor nutrition intake during pregnancy, poor nutritional status prior to pregnancy etc

More number of malformations are seen in the maternal age group 26-30 years which is comparable to studies by Neelambari YC et al. Ronya $\mathrm{R}$ et al showed more in $>35$ years $[6,13]$

The present study found that a greater number of malformations were seen in non-consanguineous marriage than consanguineous marriage and it is statistically significant in contrast to the studies by Bhat $\mathrm{B} \mathrm{V}$ et al and Ronya $\mathrm{R}$ et al $[5,13]$.

Study done by Bhat B V et al showed increase incidence of congenital malformation in male babies, but present study did not show any sex predilection similar to study done by Grover $\mathrm{N}$ et al, Taksnade et al. The male: female ratio in the present study $(1: 1.05)$ is similar to the ratio $(1: 1.05)$ in study conducted by Taksande et al $[5,9,12]$.

The incidence of congenital malformations was found to be more in premature babies compared to term babies in present study which is in accordance with the studies conducted by Taksande et al, Bhat BV et al, Sarkar et al. Neelambari $Y C$ et al found in term babies $[5,6,12]$.

In the present study thyroid disorder was the most common maternal illness associated with congenital malformations followed by oligohydramnios and polyhydramnios. Taksande et al found in maternal diabetes [12]. In present study, previous history of 


\section{Original Research Article}

abortions was found to be more associated with congenital malformations followed by previous birth defects which is similar to studies by Taksande et al, Chaturvedi $\mathrm{P}$ et al, Ronya $\mathrm{R}$ et al $[11,12,13]$.

In present study, usage of teratogenic drugs and maternal fever and infections were found to be the most common antenatal factor associated with congenital malfor-mation which is similar to the studies by Mishra PC et al, Bhat BV et al [5, 14].

Limitations : As it is a tertiary care hospital or referral centre, incidence calculated may be higher than the general population in this hospital-based study. Hence the data cannot be projected to the general population for which population-based studies are necessary. A pathological autopsy is warranted but was not performed

\section{Conclusions}

Congenital malformation continues to be a significant factor in morbidity, mortality and risk factor involved in perinatal care in our area. The overall incidence of congenital malformation was found to be 22.43 per 1000 live births and it was significantly high in still births $(10.3 / 100)$ compared to liveborn $(1.9 / 100)$ in present study.

Central nervous system malformations continue to be the most common malformation as noted by other studies followed by cardiovascular system malformations. Preventable causes teratogens, infections, other maternal factors like, thyroid disorders, diabetes, stroke, hydramnios will increase the incidence of congenital malformations where we should intervene

Recommendations: Prevention of congenital malformation can be achieved. Further studies are required with good reliable diagnostic facilities to improve the etiological factors involved in causation of malformations.

\section{What the study adds to existing knowledge?}

Though similar studies done previously. The present study noticed major portion of birth defects caused by preventable causes like maternal illness, antenatal factors, consanguineous marriage and epigenetics.

\section{Author's contributions}

Dr. Chandra Mohan Chekkali \& Dr. Himabindu Singh: Data collection.
Dr. Greeshma Reddy Kankanala: Statistical analysis.

Dr. Rakesh Kotha: Computed data and final compilation.

Funding: Nil, Conflict of interest: None initiated, Permission from IRB: Yes

\section{References}

1. Holtzman NA, Khoury MJ. Monitoring for congenital malformations. Annu Rev Public Health. 1986; 7:237-266. doi: 10.1146/annurev.pu.07.050186. 001321

2. Centres for Disease Control. Contribution of birth defects to infant mortality - United States 1986. Morbid Mortal Week Rep. 1989;38:633-635

3. Sharma R. Birth defects in India: Hidden truth, need for urgent attention. Indian J Human Genet. 2013; 19 (2):125. doi: 10.4103/0971-6866.116101

4. Patel ZM, Adhia RA. Birth defects surveillance study. Indian J Pediatr. 2005;72(6):489-491.

5. Bhat BV, Babu L. Congenital malformations at birth-a prospective study from south India. Indian J Pediatr. 1998;65(6):873-881. doi: 10.1007/bf02831352.

6. Neelambari YC, Das P, Srinivasan Sadagopan AN. Prevalence, pattern and outcome of congenital malformations in a tertiary care centre in South India. Int J Contemp Pediat. 2018;5(3):1044-1048.doi: http: //dx. doi.org/10.18203/2349-3291.ijcp20181539

7. Verma M, Chhatwal J, Singh D. Congenital malformations--a retrospective study of 10,000 cases. Indian J Pediatr. 1991;58(2):245-252. doi: 10.1007/bf 02751129

8. Agarwal SS, Singh U, Singh PS, Singh SS, Das V, Sharma A, et al. Prevalence \& spectrum of congenital malformations in a prospective study at a teaching hospital. Indian J Med Res. 1991;94:413-419.

9. Grover N. Congenital malformations in Shimla. Indian J Pediatr. 2000;67(4):249-251. doi: 10.1007/bf 02758158 .

10. Tapan pattanaik, Sunita Samal, Tanaya Jena et,al. Prevalence and Spectrum of Congenital Malformations in a Tertiary Care Centre Ind J Neonat Med Res. 2016;4 (3): 1-4. doi: 10.7860/IJNMR/2016/20253.2173. 


\section{Original Research Article}

11. Chaturvedi P, Banerjee KS. An epidemiological study of congenital malformations in newborn. Indian J Pediatr. 1993;60(5):645-653. doi: 10.1007/bf02821727.

12. Taksande A, Vilhekar K, Chaturvedi P, Jain M. Congenital malformations at birth in Central India: A rural medical college hospital-based data. Ind J Human Genet. 2010; 16(3): 159-163.doi: 10.4103/ 0971-6866. 73412
13. Ronya R, Gupta D, Ghosh SK, Narang R, Jain KB. Spectrum of congenital surgical malformations in newborns. J Indian Med Assoc. 2002;100(9):565-566.

14. Mishra PC, Baveja R. Congenital malformations in the newborn--a prospective study. Indian Pediatr. 1989; $26(1): 32-35$.

\section{How to cite this article?}

Chekkali C.M, Kankanala G.R, Rakesh K, Singh H.A profile of birth defects in a tertiary care center and focus on preventable causes: a cross sectional observational study. Int J Pediatr Res.2019;6(09):474-480.doi: 10.17511/ ijpr.2019.i09.06 